\title{
REGIONAL DIFFERENCES IN COMMUTING ACTIVITIES OF INHABITANTS IN THE TOKYO METROPOLITAN SUBURB
}

\author{
Masaki Kawase \\ Hiroshima Shudo University, Faculty of Commercial Sciences \\ I-I-I, Ozukahigashi, Asaminami-ku, Hiroshima, 73I-3195, Japan \\ e-mail: kawase@shudo-u.ac.jp
}

\begin{abstract}
The purpose of this study is to elucidate gender differences and regional differences of commuting activities by inhabitants in Japanese metropolitan suburbs. I found the different parts by districts in the metropolitan suburb. Regional factors cause gender differences in commuting activities and result in regional differences: In residential areas, inhabitants who work in metropolitan centers occupy much of the population. In older built-up areas, there are many "local" persons. In rural areas, motorization is progressing because access to railroads has been inconvenient. These regional factors influence the behavioral characteristics of commuting by married men, married women, never married men and never married women.
\end{abstract}

Key words: commuting, gender, occupation, suburb, Tokyo Metropolitan area

\section{INTRODUCTION}

Studies about gender differences related to commuting activity in cities have been much accumulated in the field of gender geography in the various English-speaking countries. The average commuting distance for women is shorter than men. These studies have paid attention to this and examined factors that make such a difference occur (Madden, 1981; Fox, 1983; Hanson, 1985). These studies tend to claim that the factor shortening commuting distances of married women's is their "two roles." These two roles refer to the fact that many women fulfill household responsibilities and also work (Blumen, 1994). Ericksen (1977) states that the age of the youngest child and marital status can explain the difference. Hanson and Pratt (1988) referred to the factor that the man tends to decide the location of the home with reference to his workplace, but it was pointed out that women tend to select a workplace with reference to their homes. Hanson and Pratt (1991) emphasized that gender differences in power relations between husband and wife in the home and social life gene- 
rated gender differences related to job hunting activities and workplace selection, and by their analysis, the job hunting process used by married women.

On the other hand, there are indications that the suburbanization of employment in a metropolitan area causes a change in the make-up of the labor force and in the entry into labor market of women, in particular (Kawaguchi, 1992). Studies that mentioned commuting of women within a metropolitan area, pointed out the importance of household attributes. Kawase $(1997,1999)$ studied a residential area of the metropolitan suburbs and mentioned gender differences in commuting activities of married persons. However, these studies did not analyze commuting activities of as yet never married person. Moreover, the characteristics of the suburbs of a metropolitan area are not the same. Therefore, we need to do comparison between areas to know what is different. I think it is important to attend to the internal structure of suburban cities when we mention the structure of a metropolitan area from a viewpoint of gender differences in commuting activities.

The purpose of this study is to elucidate gender differences and regional differences of commuting activities by inhabitants in Tokyo Metropolitan suburbs. For this study, the area surveyed was Noda City, located in the suburban region of the Tokyo Metropolitan area in Japan (Figure 1). From which the following three districts were chosen as survey districts in Noda City: the Yamazaki district, a new residential area, the Noda district as an older built-up area and the Kinosaki district as a rural area that received only limited influences of urbanization. I analyzed the data about the working people, which I collected through questionnaires and interviews, and I compared commuting activities of inhabitants between these districts. The survey was carried out from October 1998 to March 1999. Reponses were received from 119 households in the Yamazaki district, from 35 households in the Noda district, and from 24 households in the Kinosaki district.

Figure 1: Area of study

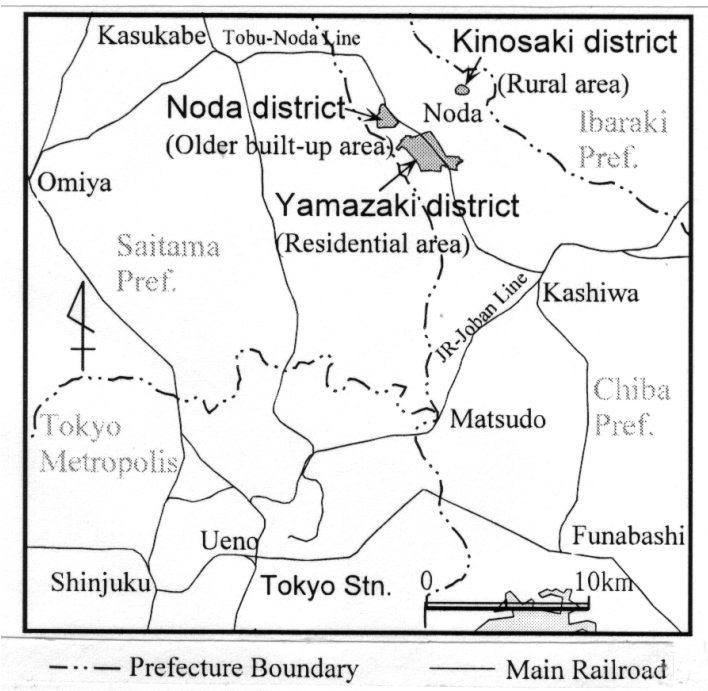




\section{COMMUTING ACTIVITIES OF INHABITANTS LIVING IN THE RESIDENTIAL AREA}

\section{Commuting activities of couples}

The distribution of workplaces of wives tends to differ greatly from that of their husbands. The average commuting time for husbands in the Yamazaki district (residential area) was 78.5 minutes (Table 1). In particular, there are many commuters working in Tokyo that can be seen the distribution of workplaces of husbands (Figure 2). Sixty-nine persons namely $73.4 \%$ from among 94 persons were commuting into Tokyo, and workplaces tended to be concentrated in three central wards of Tokyo. Many of these workers commuted to districts along the loop line (JR-Yamanote line). Workplaces were also distributed over areas where commuting time exceeds two hours such as Kanagawa Prefecture and further. The commuting activity spaces of married men were wide. Not less than the 90 percent was whitecollar workers. Electrified commuter train line users accounted for 80 percent of all commuter husbands. Most commuters going into Tokyo used these train lines.

Table 1: Average commuting time of inhabitants by marital status

\begin{tabular}{l|ccc}
\hline \multirow{2}{*}{} & \multicolumn{3}{|c}{ Average commuting time (min.) } \\
\cline { 2 - 4 } & $\begin{array}{c}\text { Yamazaki District } \\
\text { (Residential area) }\end{array}$ & $\begin{array}{c}\text { Noda District } \\
\text { (Older built-up Area) }\end{array}$ & $\begin{array}{c}\text { Kinosaki District } \\
\text { (Rural area) }\end{array}$ \\
\hline Husbands & 78.0 & 48.5 & 56.9 \\
Wives & 33.0 & 20.7 & 24.8 \\
Sons & 68.1 & 40.8 & 30.0 \\
& $(65.0)$ & - & $(38.8)$ \\
(Never married) & $(68.4)$ & $(40.8)$ & $(21.3)$ \\
Daughters & 70.4 & 53.8 & 53.0 \\
(Married) & $(20.2)$ & $(20.0)$ & $(5.0)$ \\
(Never married) & $(72.5)$ & $(60.6)$ & $(58.3)$ \\
\hline
\end{tabular}

Source: Questionnaire in 1998 and 1999

In contrast, the average commuting time for wives living in the Yamazaki district was 33.0 minutes. Twenty-two persons out of 42 commuted inside Noda City. There were many commuters to the Yamazaki district and the peripheral district in Noda City who went on foot and by bicycle. Meanwhile, only six wives commuted to Tokyo. Commuting activity spaces for wives included central wards of Tokyo, but these areas were more confined than those of husbands. Workplaces of white-collar workers were distributed throughout Tokyo and neighboring cities. In contrast, the distribution of workplaces of blue-collar workers tended to include short distance commutes from their homes. 
Figure 2: Distributions of workplaces of couples, 1998: the Yamazaki district (residential area)

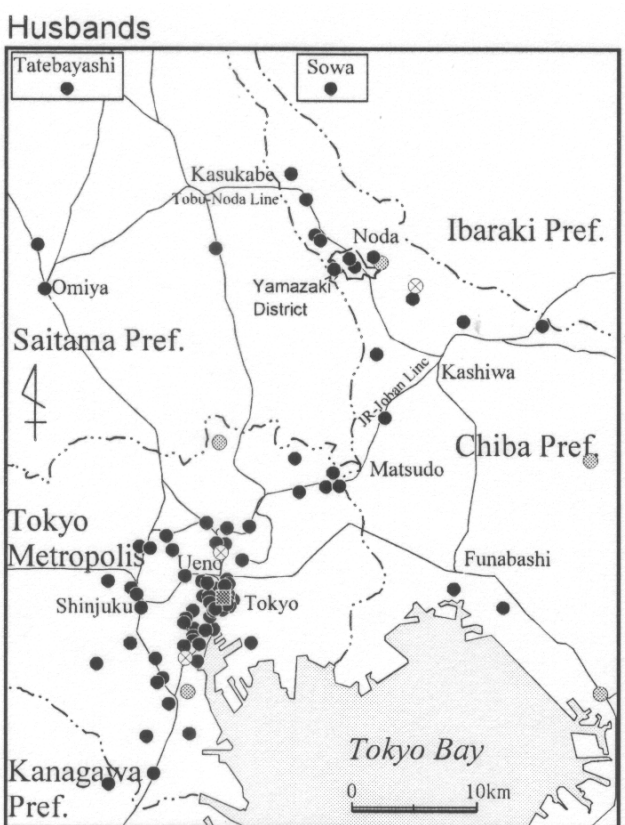

Occupation

- A White-collar Worker

- A Blue-collar Worker
Wives

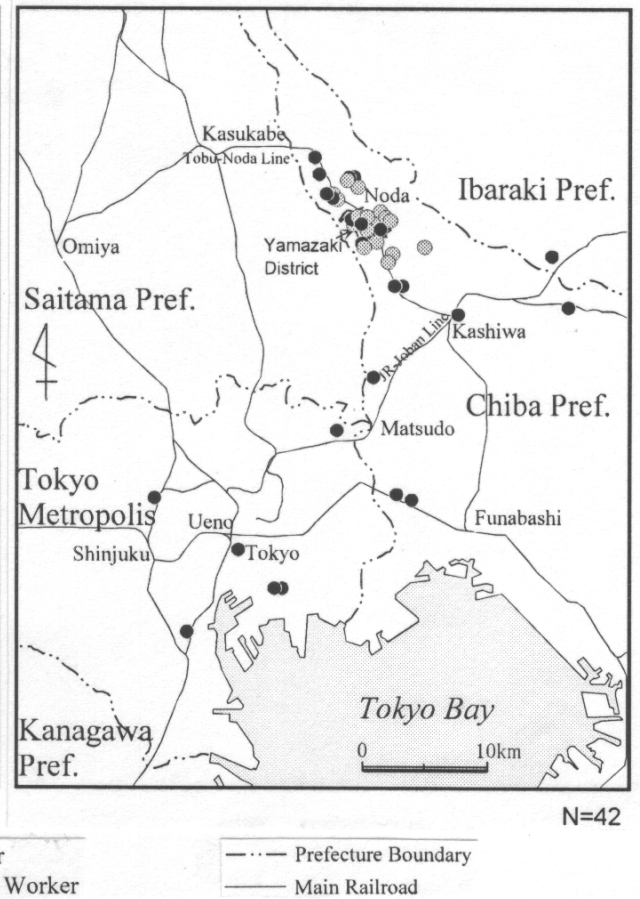

Source: Questionnaire

\section{Commuting activities of children living in the residential areas}

Commuting activity spaces of sons were relatively smaller than their fathers. The average commuting time of never married men was 68.4 minutes (Table 1). Fifteen persons $(68.2 \%)$ of 22 never married men commuted into Tokyo, and eight persons worked in areas along the loop line (Figure 3). However, only six persons worked in the three central wards of Tokyo. Meanwhile, the average commuting time for daughters was 70.4 minutes, and the average of never married women was 72.5 minutes. These results are 3.9 minutes are longer than the case of sons. Fifteen persons $(62.5 \%)$ among 24 never married women commuted into the ward area of Tokyo.

Commuting activity spaces of never married men differed significantly by occupation. Commuting activity spaces of white-collar workers including Tokyo were larger than bluecollar workers. In contrast, differences in commuting activity spaces of never married women by occupation were not clear-cut. Commuting activity spaces for both occupation groups were characterized by being involved with Tokyo.

The tendency that the average commuting time of never married men was shorter than never married women can be seen by analyzing census data of metropolitan areas in Japan. 
Figure 3: Distributions of workplaces of children, 1998: the Yamazaki district (residential area
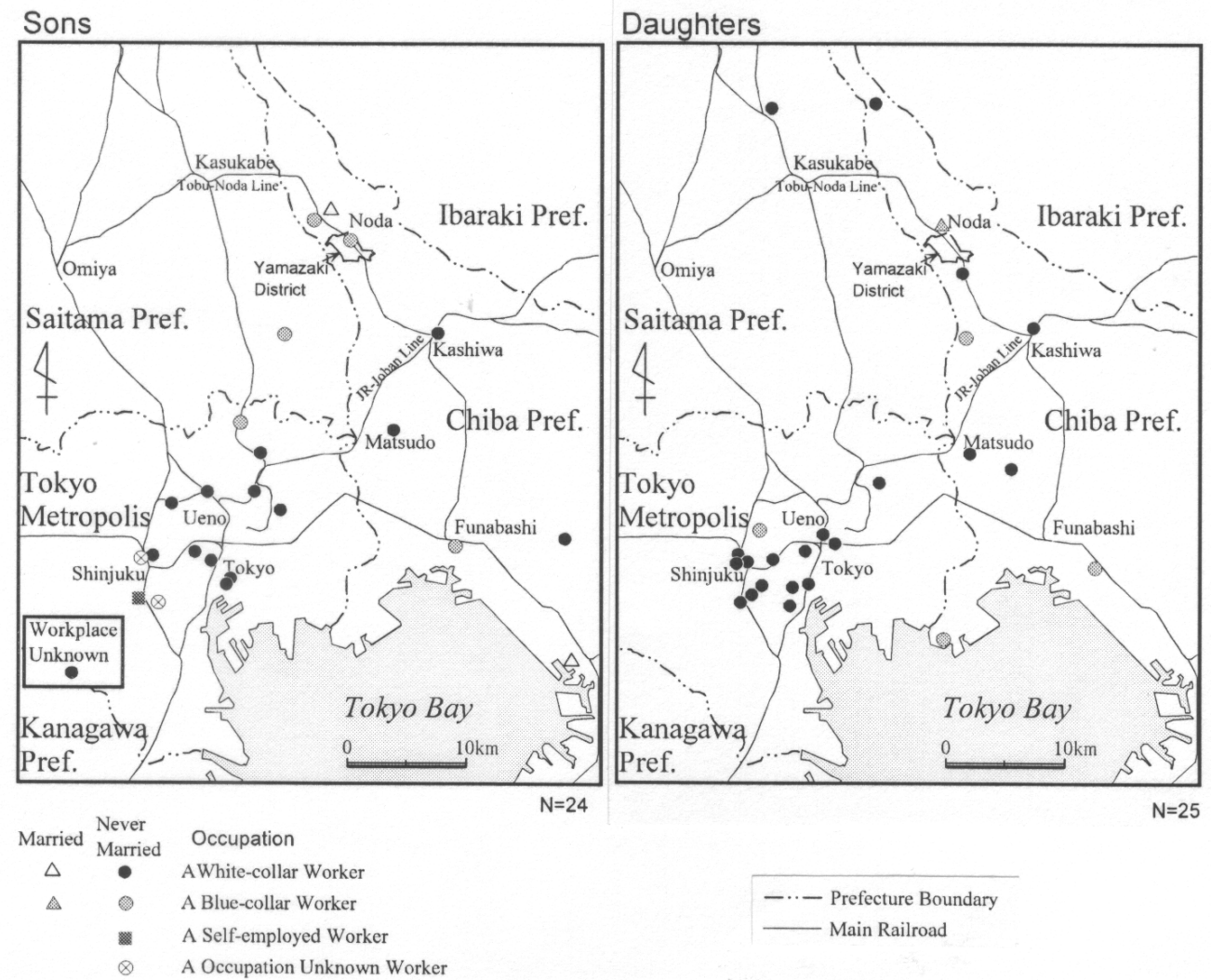

Source: Questionnaire

Why are never married women commuting distances longer than those for never married man? I indicated changes of residence in the figure, including life events such as entrance to higher education schools, finding employment and marriage and the time periods between those events (Figure 4). Most sons and daughters live at their parents' home until marriage. However, many sons left their parents' home at the stage when they received higher education at universities, and started living alone. Many sons began to live alone as soon as they found work. They began to live alone near workplaces even if they work inside or near Tokyo where they could commute to and from their parents' home in the Yamazaki district. Living alone near workplaces shortens their commuting distances. This factor strongly influences the shortness of commuting distance of never married men. On the other hand, no daughters left their parents' homes at the time they entered college, and only three daughters left the parents' home upon finding employment. Therefore, it is thought that their long distance commuting from their parents' homes was continued, and as a result, their average commuting distance become longer than never married men. 
Figure 4: Residential movement of children: the Yamazaki district (residential area)

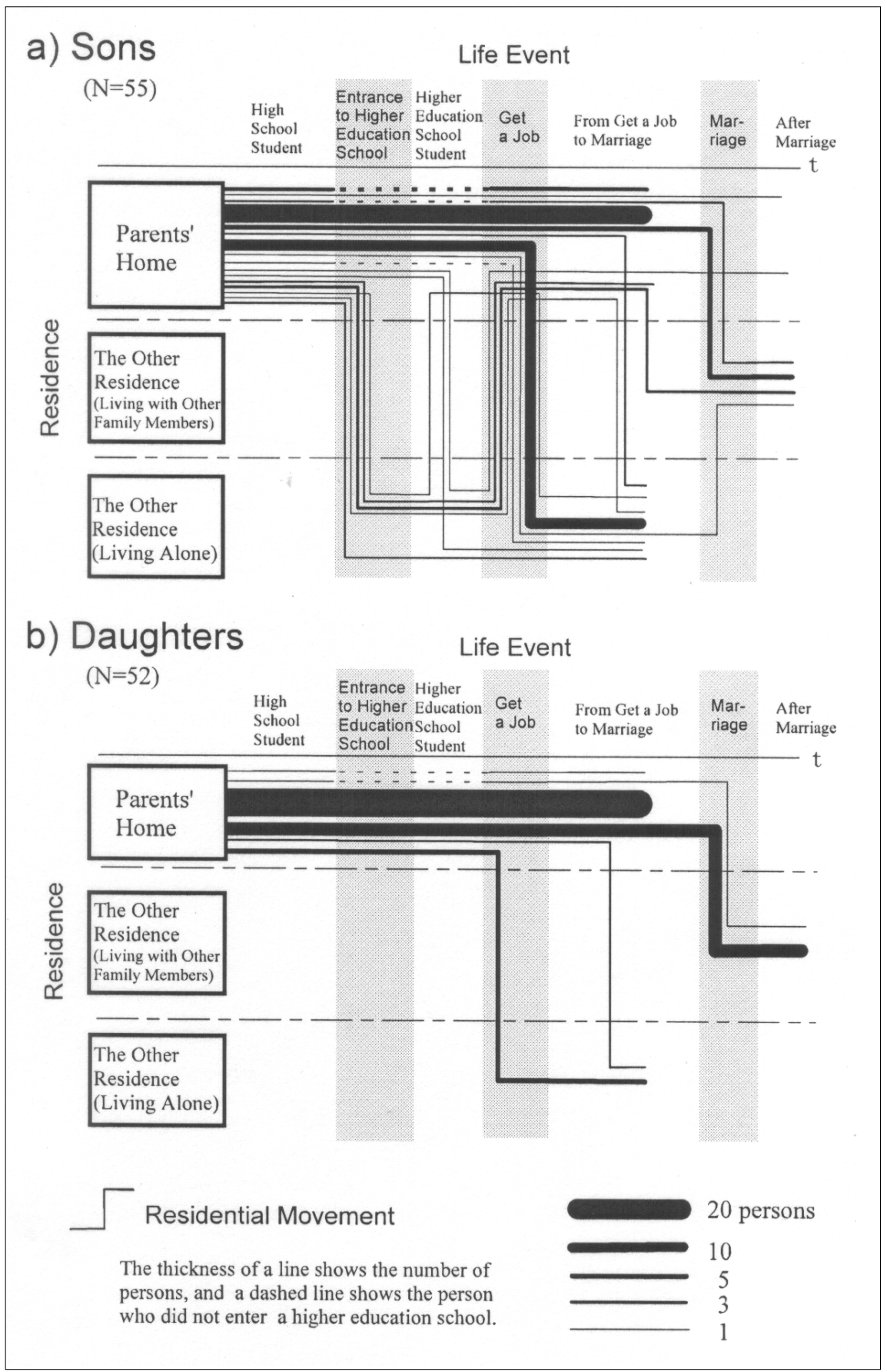

Source: Questionnaire 


\section{COMPARING COMMUTING ACTIVITIES OF INHABITANTS WITH OTHER DISTRICTS}

\section{The older built-up area}

In the Noda district that was an older built-up area, both commuting activity spaces of husbands and wives were smaller than other districts because self-employed workers for many of these respondents and there were many local workers. The average commuting time was 48.5 minutes (Table 1). This is 30.3 minutes shorter than the Yamazaki district commuters into Tokyo. Seven persons were white-collar workers among 11 persons. There are many office workers or management workers among married men who commuted even in the Noda district together with many shopkeepers. There were many employed persons living in the northeast part of the Tokyo Metropolitan area in such places as Noda, Kashiwa and Matsudo. The tendency was remarkably different from those of the Yamazaki district as a residential area. On the other hand, married female commuters consisted of only nine persons among 35 wives. However, these persons do not include wives who engage in the selfemployed work such as family employees. Wives commute in nine households among the 11 households where husband commute. Seven persons work in Noda City among nine wives, and six wives commute less than 10 minutes.

In contrast, the commuting activity spaces of children were wide and included Tokyo. The average commuting time of sons was 40.8 minutes. It was shorter than the Yamazaki district by about 18 minutes. Meanwhile, the average commuting time of never married women was 60.6 minutes.

The results differed from their parents. Commuting activity spaces of sons and daughters showed a tendency similar to the Yamazaki district as a residential area. When I compared older built-up areas with residential areas, I found as following. The generation consisting of couples showed that commuting activities are different in both districts. However, the generation consisting of their children showed similar tendencies for the two districts.

\section{Rural area}

In the Kinosaki district, a rural area, commuting by car was very common and more prevalent than the other districts.

The average commuting time of husbands was 56.9 minutes (Table 1). It was longer by 8.45 minutes than the Noda district where persons employed in the northeast suburbs of Tokyo were numerous. However it was shorter by 21.9 minutes than the Yamazaki district where many persons commute to Tokyo by train. Meanwhile, the average commuting time of wives is 24.8 minutes, less than half of husbands, and shorter by 8.2 minutes than wives' in the Yamazaki district. However, the average commuting distance was longer than the Noda district where there are many opportunities for working near home. Because it is a rural area, employment opportunities are smaller in home neighborhoods.

On the other hand, the average commuting distance for never married men was shorter than married men. The average commuting time for their sons was 30.0 minutes. However, 
the time for never married persons was 21.2 minutes and the time for married persons was 38.8 minutes. These times are extremely shorter than 56.9 minutes as the average commuting time for their husbands. Meanwhile, the commuting activity spaces for never married women are very large. The average commuting time for daughters is 53.0 minutes. In particular, the time for never married persons is 58.3 minutes. Commuters from railroad stations in this district included persons who commuted to Tokyo among whom there were husbands and daughters. Many sons work in the local outskirts and inside the prefecture, and wives worked in even smaller spatial areas.

\section{DISCUSSION}

Regional factors have led to differences between the genders and follow-on differences of commuting activities. In residential areas, regional characteristics influence commuting activity spaces by so-called "new inhabitants" who have relocated from other areas (Figure 5). Because most people who are heads of families commute to Tokyo, it may be said that the resistance to long-distance commuting to Tokyo is smaller than that from districts with many local workers. However, the working restrictions placed on women remain in such districts. Because there are many nuclear families in these residential areas, the burden of housework and childcare on housewives is heavy, so their ability to work is greatly limited. Moreover, never married women are not easily allowed by their parents to live alone. Commuting to Tokyo from Noda City is possible, and in fact, many fathers of these never married women do so. This restriction to live with one's parents is weaker for never married men than women, and some never married men leave their parents' home after finding work.

In older built-up areas, conspicuous differences are found in commuting activities between couples working near their homes and their children who end up commuting. There are many "local" self-employed workers. Many husbands and wives work locally, so time spent commuting is short. However, their sons and daughters will often spend long time to commute to metropolitan centers. Never married women who travel to metropolitan centers are prevalent and their commuting times tend to be similar to those of residential areas. I can say that a regional feature of older built-up areas is that commuting characteristics are entirely different between generations.

In rural areas, poor access to rail transport for long-distance travel and the progress of motorization are regional characteristics, and influence commuting activities greatly. Rural areas have weaker ties with metropolitan centers than other two district types, and workplaces dispersed in the suburbs. However, the progress of motorization has been made in commuting to Tokyo, except for wives, due to access from rural areas to train stations by cars. Moreover, I can say that another regional characteristic of rural areas is that many households contain three generations. In particular, many eldest sons stay at their parents' home after marriage, and live together with their parents after having children. This contributes to married women working. The ratio of working wives is higher than in urban areas. 
Figure 5: Regional differences in commuting activities of metropolitan suburbanites

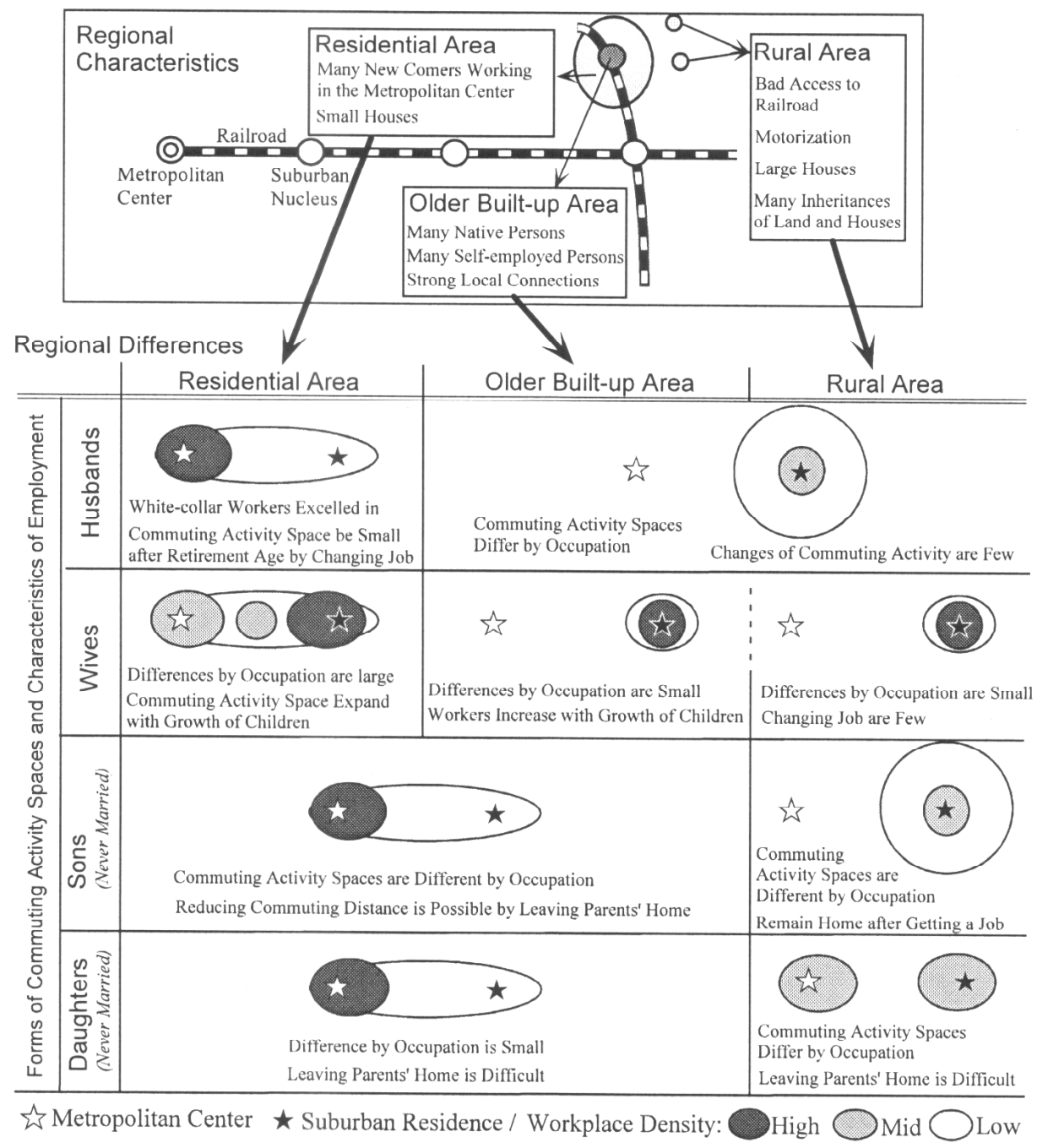

\section{CONCLUSIONS}

Regional factors cause gender differences in commuting activities and result in regional differences: In residential areas, inhabitants who work in metropolitan centers occupy much of the population. In older built-up areas, there are many "local" persons. In rural areas, motorization is progressing because access to railroads has been inconvenient. These regional factors influence the behavioral characteristics of commuting by married men, married women, never married men and never married women. 
Tokyo metropolitan suburbs have been interpreted as areas that accumulate people who have moved to Tokyo from other regions of Japan to enter a school of higher grade or to get a job. However, more recent inhabitants are born in the suburbs, and they work as "local" persons of the metropolitan suburbs, and new commuters are reproduced there. In older built-up areas, generational changes evolve in commuters. Younger generations expand the commuting activity spaces. In residential areas formed by suburbanization in the metropolitan area, there are some districts in which the average commuting distance of children is shorter than that of their fathers, because most children grow up in the metropolitan suburbs. Such children can choose workplaces inside metropolitan suburbs based on where they live, unlike their parents who came from other regions. If white-collar occupations are concentrated in the suburban nucleus with multinuclearation of the metropolitan area in the future, younger people will increasingly choose to work at selected places in the metropolitan suburbs.

\section{References}

Blumen,O., 1994: Gender differences in the journey to work. Urban Geography 15, 223-245.

Ericksen, J., 1977: An analysis of the jouney to work for women. Social Ploblems, 24, 428-435. Fox, M. B., 1983: Working women and travel: The access of women to work and community facilities. Journal of the American Planning Association, 49, 156-170.

Hanson, S., 1985: Gender differences in work-trip length: Explanations and implication. Urban Geography, 6, 193-219.

Hanson, S., Pratt, G.., 1988: Reconceptualizing the links between home and work in urban geography. Economic Geography, 64, 299-321.

Hanson, S., Pratt, G.., 1991: Job search and the occupational segregation of women. Ann. Assoc. Amer. Geogr., 81, 229-253.

Kawaguchi, T., 1992: A study on activity space of suburban residents. Regional Views, 5, 83-99. (in Japanese)

Kawase, M., 1997: Changes in married women's commuting activity in terms of life-stage in Kashiwa, Chiba Prefecture. Geographical Review of Japan, 70A, 699-723. (in Japanese with English abstract)

Kawase, M., 1999: Commuting activity of married women in a suburb of the Tokyo metropolitan area. GeoJournal 48: 217-222.

Madden, J. F., 1981: Why women work closer to home?. Urban Studies 18: 181-194. 